Article

\title{
Long Term Impact of Grid Level Energy Storage on Renewable Energy Penetration and Emissions in the Chilean Electric System
}

\author{
Serguey A. Maximov, Gareth P. Harrison and Daniel Friedrich * (1) \\ Institute for Energy Systems, School of Engineering, University of Edinburgh, Edinburgh EH9 3DW, UK; \\ serguey.maximov@ed.ac.uk (S.A.M.); gareth.harrison@ed.ac.uk (G.P.H.) \\ * Correspondence: d.friedrich@ed.ac.uk; Tel.: +44-(0)131-650-5662
}

Received: 15 February 2019; Accepted: 12 March 2019; Published: 20 March 2019

check for updates

\begin{abstract}
Chile has abundant solar and wind resources and renewable generation is becoming competitive with fossil fuel generation. However, due to renewable resource variability their large-scale integration into the electricity grid is not trivial. This study evaluates the long-term impact of grid level energy storage, specifically Pumped Thermal Energy Storage (PTES), on the penetration of solar and wind energies and on $\mathrm{CO}_{2}$ emissions reduction in Chile. A cost based linear optimization model of the Chilean electricity system is developed and used to analyse and optimize different renewable generation, transmission and energy storage scenarios until 2050. For the base scenario of decommissioning ageing coal plants and no new coal and large hydro generation, the generation gap is filled by solar photovoltaic (PV), concentrated solar power (CSP) and flexible gas generation with the associated drop of $78 \%$ in the $\mathrm{CO}_{2}$ emission factor. The integration of on-grid $8 \mathrm{~h}$ capacity storage increases the solar PV fraction which leads to a $6 \%$ reduction in operation and investment costs by 2050. However, this does not necessarily lead to further reductions in the long term emissions. Thus, it is crucial to consider all aspects of the energy system when planning the transition to a low carbon electricity system.
\end{abstract}

Keywords: linear optimization; pumped thermal energy storage; grid energy storage; renewable integration; Chile

\section{Introduction}

Chile has significant potential for renewable energy but its long and narrow shape poses a challenge for the integration of renewable energy into the electricity system. In particular, the values of annual global horizontal irradiance (GHI) and direct normal irradiance (DNI) reach up to $2700 \mathrm{kWh} / \mathrm{m}^{2} /$ year and up to $3700 \mathrm{kWh} / \mathrm{m}^{2} /$ year respectively in the northern area. However, in 2012 the System Operator warned that $450 \mathrm{MW}$ was the maximum capacity of intermittent generation which could be deployed in the northern system due to grid restrictions [1]. In the last years this level has increased, mostly due to improvements in the transmission capacity, especially with the interconnection of the Northern Interconnected System (SING) and the Central Interconnected System (SIC). In 2018, there were $2250 \mathrm{MW}$ of photovoltaic (PV) and $1520 \mathrm{MW}$ of wind generation in operation according to data from the National Energy Commission [2], which represents around $16 \%$ of the total installed capacity. Nevertheless, in order to sustain the continued deployment of these technologies, further grid improvements are required. Moreover, according to the Energy Roadmap for 2050, under the current electric grid structure, it is only possible to generate up to $41 \%$ of energy from intermittent renewables [3]. Therefore, with the aim of reaching the goal of $70 \%$ of electricity from renewables by 2050 [3,4], it is necessary to increase the operational flexibility of the grid, with energy storage 
being one of the most interesting alternatives. Munoz et al. [5] showed that from a market perspective achieving $70 \%$ renewables was possible even without additional policies such as promotion of energy storage. However, there are some technical constraints that could hinder achieving this target and a more detailed analysis is required.

Due to the Chilean geography, the Chilean electricity network has a radial topology. This characteristic increases the probability of bottlenecks and constrains the ability of transmitting large amount of energy along the country. Furthermore, until 2017 the two main electric systems (SIC and SING) were not connected, hindering the possibility of supplying the cities and industries in the central area of Chile (around the cities of Santiago and Concepcion) with electricity produced with clean solar technology in the North. This changed in late 2017 after the interconnection of the two main electricity systems, as now over $99 \%$ of the installed capacity is connected and coordinated by an independent centralized authority. The $400 \mathrm{~km}, 500 \mathrm{kV}$ interconnection allows to transfer energy between the northern part of the system, abundant in solar resource and the rest of the country, where more than $90 \%$ of the population resides.

However, there are still many barriers for a higher integration of intermittent renewable generation into the grid. In this sense, Haas et al. [6] analysed the different economical, regulatory and technical barriers that prevent higher penetration of solar energy in Chile. Two of the main technical barriers are the constraints in transmission capacities, also highlighted by [7] and the lack of backup flexibility. Energy storage technologies such as batteries, pumped hydro, molten salts and hydrogen could provide this flexibility and should be assessed in the context of increased non-dispatchable renewable generation. However, to achieve the large scale integration of intermittent renewables and energy storage it is important to reform the market and regulatory framework which was designed for conventional and dispatchable electricity generation [8,9]. For example, energy storage systems can provide a number of services and roles, such as frequency response service and short term operating reserve but most markets have limited mechanisms to enable this stacking of services [9].

A number of researchers have assessed the impact of energy storage in Chile's electric system. For instance, Moreno et al. [10] analyse the effects of pumped hydro on the integration of renewables in Chile and assess the value of adding storage in the Chilean system. In particular, they evaluate the conversion of conventional hydropower generators to pumped hydro storage plants. Interestingly, they show that this transformation has better synergies with solar PV than with wind generation due to wind production being more distributed during the day if compared with solar. Suazo-Martinez et al. [11] present a framework for the optimization of energy storage sizing. They apply the methodology to optimally size pumped hydro-like energy storage in the former SING system to provide secondary reserve and energy arbitrage services for the period between 2020 and 2030. They show that the optimal installed capacity of storage in that system depends strongly on the investment costs but for pumped hydro costs of $400-900 € / \mathrm{kW}$ and $17 € / \mathrm{kWh}$ it is between 100 and $200 \mathrm{MW}$ of installed capacity and energy capacities between 5 to $10 \mathrm{~h}$.

Within the multiple options for electricity storage, thermal energy storage presents some relative advantages with respect to other energy storage technologies. Probably, the most important is that it has no geographical or geological constraints, such as those presented by pumped hydro or compressed air storage (CAES). In addition, it uses only relatively common and non-hazardous materials in comparison with chemical storage and it is potentially cheaper than the different available battery storage technologies [12]. The first point is particularly important in the Chilean case, because all the existent hydroelectric dams that could potentially be converted to pumped storage are located in the South, while the solar resource is located in the North and the main demand is in the middle. Alternatively, pumped hydro storage located in the North using sea water has been assessed and the start of building of a $300 \mathrm{MW}$ project is scheduled for 2020. However, the costs of this project are close to $1400 € / \mathrm{kW}$ [13].

Pumped Thermal Energy Storage (PTES) is a thermo-mechanical energy storage technology that uses electrically-driven heat pumps with high coefficient of performance (COP) to create a temperature 
difference between two thermal reservoirs. When electricity is needed, the system operates backwards and uses the temperature difference to drive a thermal cycle to generate electricity [14]. PTES is expected to achieve efficiencies around 70\% [15] and under a levelized cost of storage analysis (LCOS), it could be competitive with other more developed large-scale energy storage technologies, such as CAES and even pumped hydro [16].

By 2018, there are only $54 \mathrm{MW}$ of electricity storage in form of lithium-ion batteries connected at grid level in Chile [17]. While it is clear that more energy storage is required to achieve the goal of $70 \%$ of electricity from renewables, it is not clear how much and where the energy storage should be deployed to enable the large scale deployment of renewable generation. Integrated simulation and optimization methods of the complete electricity system are required due to the complex interplay between generation, transmission and energy storage.

This work presents a quantitative analysis of the long-term impact of on-grid storage on the deployment of intermittent generation technologies in the recently connected Chilean national electric grid. A linear optimization model is used to model the Chilean electricity system and to assess a number of scenarios with variable on-grid electricity storage. As part of this analysis, it assesses the use of a new storage technology (PTES), considering its efficiency, projected investment and operational costs.

\section{Materials and Methods}

The model of the Chilean energy system used in this work is a linear programming optimization model based on "urbs" [18] with additions and modifications to account for the water storage capacity of hydroelectric dams and the thermal storage of concentrated solar power (CSP) plants. Urbs is a model written in Python 3 [19] which relies on Pyomo [20] for optimization set-up and on Gurobi [21] as solver.

The objective function of the model is the minimization of the annual electricity system cost. In its most general form this cost is calculated as

$$
C=C_{i n v}+C_{f i x}+C_{v a r}+C_{f u e l}+C_{e n v}
$$

where $C_{i n v}$ is the investment cost of that year over the life span, $C_{f i x}$ is the fixed cost of operation of each technology, $C_{v a r}$ is the variable cost of operating the technology, $C_{f u e l}$ is the cost of the fuel for operating the technology and $C_{e n v}$ is an environmental cost associated to a carbon tax. These costs are calculated for generation, transmission and storage technologies and a weighted average cost of capital (WACC) of $7 \%$ is used to spread the investment cost over the lifetime of the technology.

The main constraint of supplying the electricity demands in each node in each time step is given by

$$
D_{i} \leq G_{i}+\sum_{j} T_{i j}-S_{i}+R_{i}
$$

where $D_{i}$ and $G_{i}$ represent the demand and generation in node $i, T_{i j}$ represent the energy transmitted between nodes $i$ and $j$ and $S_{i}$ and $R_{i}$ the energy stored and retrieved from storage in the node. Other constraints are the minimum and maximum capacities of the units and can be checked in reference [18].

The minimization model is solved for one year using a one-hour time step. For each time step, the model defines the unit commitment of each available technology, the energy transmitted between nodes and the energy stored and retrieved. It also calculates whether it is economically convenient to invest in more installed capacity of a given generation technology, transmission or storage at the beginning of that year. In order to assess the long-term behaviour of the system, the model is run from 2020 to 2050 every 5 years, considering the installed capacity output of the year $x$ as input for the year $x$ +5 and the evolution in demand and change in costs of investment and operation of the technologies.

The Chilean electric system was modelled as a four nodes system numbered from north to south, as shown in Figure 1. This number of nodes was chosen as an approximation of the real system that would allow to capture the main specific characteristics in energy resources availability and electrical 
consumption of the different areas of Chile, while keeping the computational complexity manageable. Some of these main characteristics for each node are:

- Node 1: It represents the former SING system, which was not connected to the rest of the country until 2017, meaning it was self-sufficient. It accounts for $25 \%$ of the total demand with a relatively flat daily consumption profile due to high share of $24 / 7$ operating mining industry. It has the highest potential for solar energy but its current installed capacity is mostly coal and combined cycle gas plants (CCGT).

- Node 2: It represents the northern part of the former SIC system and accounts for only $15 \%$ of the demand and presents a high solar potential. Currently it has a combination of wind, solar and fossil fuel (coal, gas and diesel) generation.

- Node 3: It represents the central part of the former SIC system, home to more than $60 \%$ of the population and accounts for around $43 \%$ of the total demand. Its installed capacity is a mixture of hydropower, CCGT and coal power plants. It does not have especially good renewable resources and it is historically a net importer of energy.

- Node 4: It represents the southern part of the former SIC system with only $15 \%$ of the demand but high installed capacity of hydro power and good wind potential. It has been historically a net exporter of electricity.
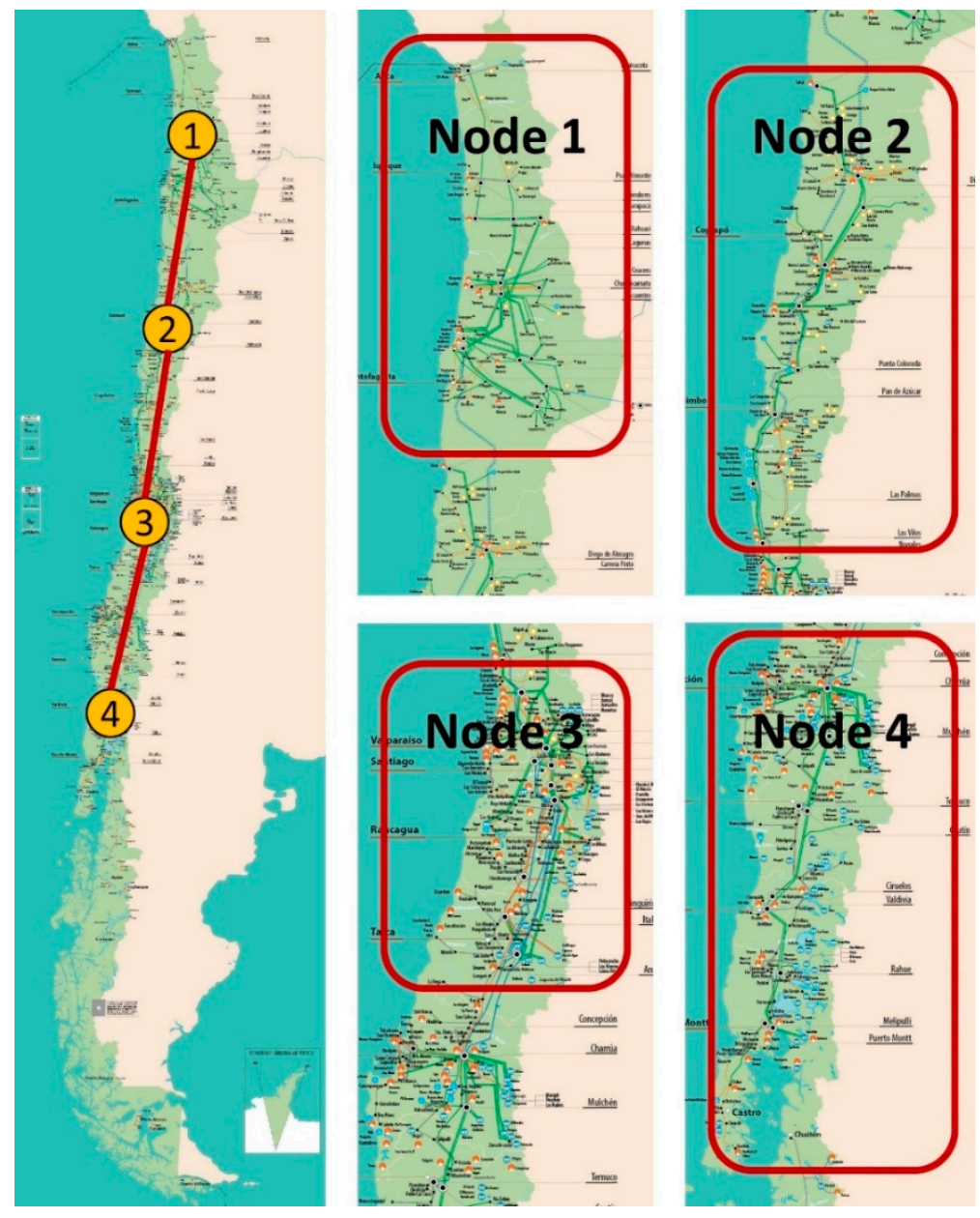

Figure 1. Nodes considered in the model [22].

\subsection{Installed Capacity}

The system was modelled according to the 2016 configuration, prior to the connection of SIC and SING. The data for the installed capacity per technology (shown in Table 1) were obtained from the 
National Electric Coordinator (NEC). For the year 2020, projects in the pipeline of the Chilean National Expansion Plan are added [23]. These include Cerro Dominador project (110 MW), the first CSP project in South America that considers molten salt storage tanks with a capacity of $17.5 \mathrm{~h}$ of operation. Slack power plants are included in each node with infinite capacity and high operational cost, ensuring that the condition in Equation (2) is always met. The cost of operation of these slack power plants is equal to short duration unmet load in the system, according to [24].

Table 1. Installed capacity per node for 2016 in MW.

\begin{tabular}{cccccc}
\hline Generation Technology & Node $\mathbf{1}$ & Node $\mathbf{2}$ & Node $\mathbf{3}$ & Node $\mathbf{4}$ & Total \\
\hline Coal & 1959 & 694 & 805 & 850 & 4308 \\
OCGT & 53 & 237 & 262 & 60 & 612 \\
CCGT & 1745 & 0 & 1883 & 0 & 3628 \\
Diesel & 232 & 840 & 860 & 912 & 2844 \\
Hydro reservoir & 0 & 0 & 1645 & 1775 & 3420 \\
Hydro streaming & 0 & 0 & 1559 & 1554 & 3113 \\
Biomass & 0 & 0 & 101 & 362 & 463 \\
Geothermal & 17 & 0 & 0 & 0 & 17 \\
Wind & 200 & 709 & 18 & 93 & 1020 \\
Photovoltaic & 259 & 578 & 46 & 0 & 883 \\
CSP & 0 & 0 & 0 & 0 & 0 \\
Total & 4465 & 3058 & 7179 & 5606 & 20,308 \\
\hline
\end{tabular}

It is important to notice that the units of the same technology located in a same node are treated as a single power plant with the equivalent capacity.

\subsection{Transmission}

Transmission between nodes was approximated by the capacity of the main lines that join the main areas of the system according to Table 2. The presented efficiencies represent losses of $2.3 \%$ of the total generation in the transmission lines. This capacity was increased every 10 years, following the increase in total demand. It was assumed that the transmission between nodes 2 and 3 would increase $60 \%$ faster to allow the transmission of the solar generation to the point of higher consumption.

Table 2. Transmission line capacities and efficiencies for Scenarios 0 to 4 .

\begin{tabular}{cccccc}
\hline \multirow{2}{*}{ Transmission Line } & \multirow{2}{*}{ Efficiency } & \multicolumn{4}{c}{ Capacity [MW] } \\
\cline { 3 - 6 } & & $\mathbf{2 0 2 0}$ & $\mathbf{2 0 3 0}$ & $\mathbf{2 0 4 0}$ & $\mathbf{2 0 5 0}$ \\
\hline Node 1-Node 2 & 0.85 & 1500 & 1756 & 2012 & 2269 \\
Node 2-Node 3 & 0.9 & 1500 & 1910 & 2320 & 2730 \\
Node 3-Node 4 & 0.9 & 2000 & 2342 & 2683 & 3025 \\
\hline
\end{tabular}

\subsection{Investment and Operational Costs}

Costs for investment, operation and fuel were obtained from the average scenario in Chile's Long Term Energy Plan [25]. Table A1 (Appendix A) shows the investment costs of renewable energies and the projected cost of fuels used in the model. The lifespans assumed for the annualization of the investment cost are 40 years for coal and geothermal, 30 for CCGT and OCGT, 25 for diesel engines, CSP, wind, PV and biomass and 20 for PTES.

\subsection{Hourly Demand}

Hourly electricity demand was obtained from the National Electric Coordinator [26] for 2016 for SING (node 1) and SIC. The regional National Energy Balance 2016 [27] is used to spread SIC's total demand between the nodes 2 to 4 . For projecting the demand until 2050, a linear model, which is 
fitted with the demand for 2016 and the projected demand for 2046 from [25], is used for the entire country. This growth is spread between the four nodes according to the expected growth trends of total energy consumption presented in Reference [25]. Like any projection, the demand forecast from the Ministerio de Energía of Chile is based on a large number of assumptions such as projections of population growth, energy productivity, sustainable behaviour as well as increasing share of electric vehicles and electric heating.

\subsection{Renewable Resource}

The hourly data for solar and wind resource were obtained from [28] as capacity factors. In the case of solar PV, the capacity factor corresponds to an optimally tilted (maximizing annual generation) fixed array. In the case of wind, it considers a conventional turbine with $50 \mathrm{~m}$ hub height.

In order to get a better representation of the existing renewable projects, the geographical data points were chosen to match the location of existing clusters of plants, as shown in Table 3 . In the case of solar for nodes 3 and 4 , considering the comparatively lower solar resource, the main cities were chosen to account for mostly rooftop systems which are expected to be installed in these areas.

Table 3. Locations used for solar and wind data for each node.

\begin{tabular}{|c|c|c|c|c|c|}
\hline & & Name of Location & Latitude & Longitude & Average Capacity Factor \\
\hline \multirow{2}{*}{ Node 1} & Solar & María Elena & -22.34 & -69.66 & 0.249 \\
\hline & Wind & Valle de los Vientos & -22.48 & -68.82 & 0.191 \\
\hline \multirow{2}{*}{ Node 2} & Solar & Diego de Almagro & -26.39 & -70.04 & 0.237 \\
\hline & Wind & Los Cururos & -31.05 & -71.63 & 0.206 \\
\hline \multirow[b]{2}{*}{ Node 3} & Solar & Santiago & -33.44 & -70.65 & 0.213 \\
\hline & Wind & Ucuquer & -34.04 & -71.63 & 0.143 \\
\hline \multirow{3}{*}{ Node 4} & Solar & Temuco & -38.73 & -72.58 & 0.181 \\
\hline & Wind (existent) & Renaico & -37.72 & -72.59 & 0.194 \\
\hline & $\begin{array}{c}\text { Wind (after } \\
\text { 2025) }\end{array}$ & Osorno costa & -41.00 & -73.84 & 0.295 \\
\hline
\end{tabular}

Solar and wind resources are considered to be constant during the analysed period. However, a location with higher capacity factor is chosen after 2025 because it is expected that in the near future locations with better wind resources that are currently far from the main transmission lines are going to be developed due to the expansion of the transmission system. For the hydroelectric generation, the average hourly capacity factor of the existing off-the-river hydroelectric power stations was used. These capacity factors were decreased by $0.386 \%$ /year from 2025 to 2040 and by $0.737 \%$ /year from 2040 to 2050 in order to account for the impact of climate change in the main Chilean basins, in accordance to [29], which predicts a reduction in annual rainfall.

The maximum potential of renewable generation at each node was defined according to the limits set by [30] and are presented in Table 4 . The maximum capacity for conventional generation was left unconstrained but it was considered that no coal power plants were to be constructed after 2025, taking into account the agreement between the Ministry of Energy and the Electricity Generator's Association [31].

Table 4. Maximum capacity of renewable generation to be installed in each node [MW].

\begin{tabular}{ccccc}
\hline & Node 1 & Node 2 & Node 3 & Node 4 \\
\hline Wind & 11,000 & 1152 & 150 & 24,000 \\
Photovoltaic & 700,000 & 140,000 & 7500 & 7500 \\
CSP & 380,000 & 29,000 & 0 & 0 \\
Geothermal & 1000 & 0 & 500 & 100 \\
Biomass & 0 & 0 & 200 & 1000 \\
\hline
\end{tabular}




\subsection{Scenarios}

To assess the impact that on-grid storage can have in the Chilean electricity system in the long term, 6 scenarios with different energy storage and transmission expansions are analysed. The details of the storage for Scenarios 0 to 3 are shown in Table 5, while the results of storage optimization for Scenarios 4 and 5 are presented in Section 3.2. The first scenario (Scenario 0) can be considered "business as usual" and it does not consider any on-grid electricity storage. Three exploratory scenarios with different amounts of on-grid storage were considered (Scenario 1, Scenario 2 and Scenario 3). These scenarios consider a fixed amount of storage deployed on the grid. Scenario 1 was constructed by considering $50 \%$ of the installed storage capacity achieved by running the model under very favourable conditions for storage deployment: demand and prices for 2050 but considering an initial installed capacity as for 2020 and a low price for storage (350,000 €/MW and $50 € / \mathrm{MWh})$. Scenario 2 considers an increase on energy storage capacity to $30 \mathrm{~h}$ without changing the installed storage power capacity, while Scenario 3 considers an increase of $30 \%$ of the installed storage power capacity, keeping the $8 \mathrm{~h}$ of storage. A more realistic scenario (Scenario 4) considered the availability of pumped thermal energy storage (PTES) at a cost according to Table 6 . As all the previous scenarios assumed a fixed increase in the transmission, Scenario 5 is an exploratory scenario to assess the transmission system upgrade under the option of higher storage penetration in the grid. Scenario 5 considers the same cost of storage as Scenario 4 but instead of assuming a transmission expansion according to Table 2, it assumes a cost for expanding the transmission capacity and includes that decision in the optimization model. In order to analyse the influence of the cost of expansion, two versions of scenario 5 are created: Scenario $5 \mathrm{a}$ with costs of $400,000 € / \mathrm{MW}$ (approximately equivalent to $900.000 € / \mathrm{km}$ ) and Scenario $5 \mathrm{~b}$ with an expansion cost of 250,000 $€ /$ MW (approximately equivalent to 550,000 $€ / \mathrm{km}$ ). These values are based on an average distance of $650 \mathrm{~km}$ between each node and a double circuit of $500 \mathrm{kV}$, with $1500 \mathrm{MW}$ of capacity.

Table 5. Installed capacity of storage for Scenarios 1, 2 and 3 in year 2050.

\begin{tabular}{lcccccc}
\hline & & Node 1 & Node 2 & Node 3 & Node 4 & Total \\
\hline \multirow{2}{*}{ Scenario 0 } & Storage power by 2050 [MW] & 0 & 0 & 0 & 0 & 0 \\
& Storage energy by 2050[h] & 0 & 0 & 0 & 0 & 0 \\
Scenario 1 & Storage power by 2050 [MW] & 2806 & 3252 & 606 & 606 & 7270 \\
& Storage energy by 2050 [h] & 8 & 8 & 8 & 8 & 8 \\
Scenario 2 & Storage power by 2050 [MW] & 2806 & 3252 & 606 & 606 & 7270 \\
& Storage energy by 2050 [h] & 30 & 30 & 30 & 30 & 30 \\
Scenario 3 & Storage power by 2050 [MW] & 3648 & 4228 & 788 & 788 & 9451 \\
& Storage energy by 2050 [h] & 8 & 8 & 8 & 8 & 8 \\
\hline
\end{tabular}

Table 6. Projected investment cost for pumped thermal energy storage (PTES).

\begin{tabular}{cccccccc}
\hline & $\mathbf{2 0 2 0}$ & $\mathbf{2 0 2 5}$ & $\mathbf{2 0 3 0}$ & $\mathbf{2 0 3 5}$ & $\mathbf{2 0 4 0}$ & $\mathbf{2 0 4 5}$ & $\mathbf{2 0 5 0}$ \\
\hline Power investment cost $[€ / \mathrm{kW}]$ & 800 & 725 & 650 & 575 & 500 & 425 & 350 \\
Energy investment cost $[€ / \mathrm{kWh}]$ & 20 & 18.83 & 17.67 & 16.5 & 15.3 & 14.17 & 13 \\
\hline
\end{tabular}

\subsection{Pumped Thermal Energy Storage Modelling}

The PTES model is based on the work of Smallbone et al. [16]. The roundtrip efficiency was set at $67 \%$, according to the target system, while the self-discharge rate was set to $1 \% /$ day. The investment costs were set at the conservative estimate for 2020 and shifted linearly towards the technical potential by 2050 , in accordance to Table 6 . For this kind of technology, the addition of extra energy capacity is straight forward, as it depends mostly on the size of the tanks, which is independent of the power capacity. Thus, both costs can be added without incurring double counting, as the power investment cost depends primarily on the cost of the compression/expansion equipment, while energy investment costs depend on the size of the tanks and the quantity of the energy storage material. 


\subsection{CSP and Hydroelectric Reservoir Modelling}

The underlying model (urbs) allows to generate, consume, transfer and store different resources. However, it does not include the possibility of directly storing intermittent renewable energies, as these are provided as a capacity factor from 0 to 1 and not as an energy flow. Thus, an intermediate commodity had to be used to allow for storing energy before its conversion to electricity. Figure 2 shows this logic for CSP and hydroelectric power plants with reservoirs.

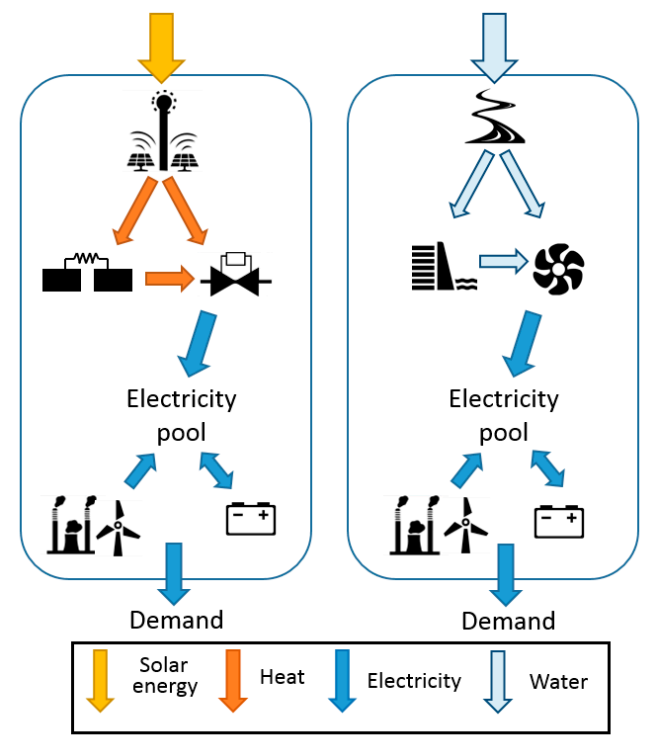

Figure 2. Scheme of the modelling of concentrated solar power (CSP) (left) and hydroelectric power stations (right) with storage.

In the case of CSP, the solar direct normal irradiation (DNI) expressed as a capacity factor is transformed into heat by the solar field. The heat can be transformed into electricity by the power block or stored in the thermal storage, from where it can be retrieved to generate electricity later. In the case of the hydroelectric dams, the river water influx expressed as a capacity factor of an equivalent off-the-river power station is transformed into energy-equivalent dammed water, which can be used to generate electricity in the turbine or stored for later use. In this case, the turbine has an additional operational cost of $30 € / \mathrm{MWh}$ to simulate the opportunity cost of using the stored water to generate electricity instead of storing it for future uses.

While CSP power plants may have different combinations of solar field, storage and power block sizes, the Cerro Dominador power plant was used as a model for the new added capacity. This means that all the new CSP capacity added to the system have a solar multiple of 2.5, power block efficiencies of $37 \%$ and $17.5 \mathrm{~h}$ of thermal storage capacity. These values also agree with the optimal values found by Bravo et al. [32].

\subsection{Other Important Assumptions}

- It is assumed that there is no expansion of coal generation from 2025. This is based on the agreement signed in early 2018 between the government and the generation sector that no new coal fired power plants are developed unless they are equipped with carbon capture and storage [31].

- The obsolescence of the existing power stations was considered and the installed capacity was decreased in each period taking into account their initial year of operation and expected lifespans. While new plants are usually designed for a lifespan of 15 and 25 years for diesel and gas/coal, respectively, most plants have their lifespan extended by 5 to 15 years [33,34]. Here, lifespans of 25 years for diesel engines, 30 years for OCGT and CCGT and 40 years for coal power plants are 
assumed. The same lifespans are assumed for the newly installed capacity, so no decommissioning of new units is considered during the annualized timeframe.

- Another important assumption is that there is no new development of large hydropower projects. This strong assumption is based on the opposition that these projects had in recent years $[35,36]$ and aims to show that a high percentage of electricity from renewables is achievable even without the construction of large hydroelectric projects.

- It is considered that there is no limitation on availability of fuels for the operation of the conventional power plants (coal, natural gas and diesel) and biomass power plants and that there is no limitation of maximum installed capacities of conventional generation technologies (other than coal).

- Chile was the first country in South America to introduce a carbon tax of $5 \mathrm{US} \$ / \operatorname{tonCO} \mathrm{O}_{2}$ in 2017 [37]. Using the conversion of $1 \$=1 €$, a $5 € /$ tonCO $\mathrm{CO}_{2}$ fixed carbon tax is considered for all the modelled scenarios. This low carbon tax will have limited impact on the decarbonisation of the power sector and was introduced with the aim of implementing the regulatory framework, infrastructure and social acceptability [38].

\section{Results and Discussions}

First, the results and discussion of the scenarios with fixed energy storage (Scenario 1, 2 and 3) and subsequently the results of the scenarios with optimized storage (Scenarios 4 and 5) and transmission expansion (Scenario 5) are presented. In all the cases Scenario 0 is used as a reference scenario.

\subsection{Scenarios 1,2 and 3}

As shown in Table 5, Scenarios 1, 2 and 3 do not include energy storage in the optimization formulation, meaning that its addition is an exogenous process and is seen as "free" from the systems perspective. After running the model for the different scenarios, it is evident that storage has an impact in the amount of non-dispatchable renewable capacity that is installed in the system, as is shown in Figure 3.

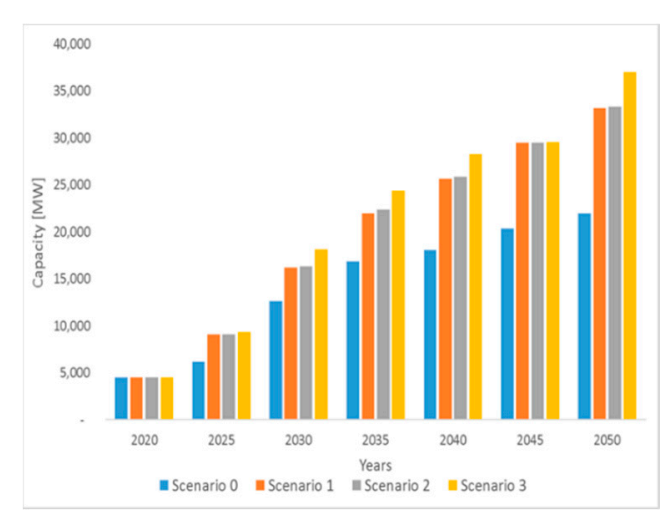

(a)

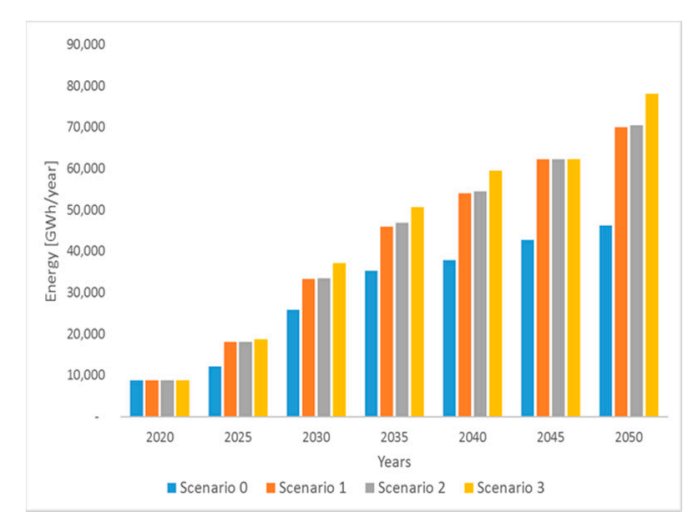

(b)

Figure 3. Evolution of the installed capacity (a) and energy generation (b) of PV and wind under Scenarios 1,2 and 3.

Figure 3a shows that in the long-term in Scenario 0 (no storage) there is already an important increase in the installed capacity of non-dispatchable renewables. This increase is mostly due to PV, which is cheaper than wind. In addition, northern Chile has a very good solar resource which together with the daily solar cycle leads to strong synergy with energy storage systems with capacity for around half a day. However, it is worth to mention that the relative increase in wind generation capacity is higher in the scenario with no storage, as shown in Figure 4a. This is probably due to wind being on average more evenly distributed during the day. This agrees with Moreno et al. [10], who showed that 
the development of solar PV increases the value of pumped hydro projects more than wind energy. However, energy storage systems with capacity for more than a day lead to a relative increase in wind generation capacity due to the less regular wind resource profile.

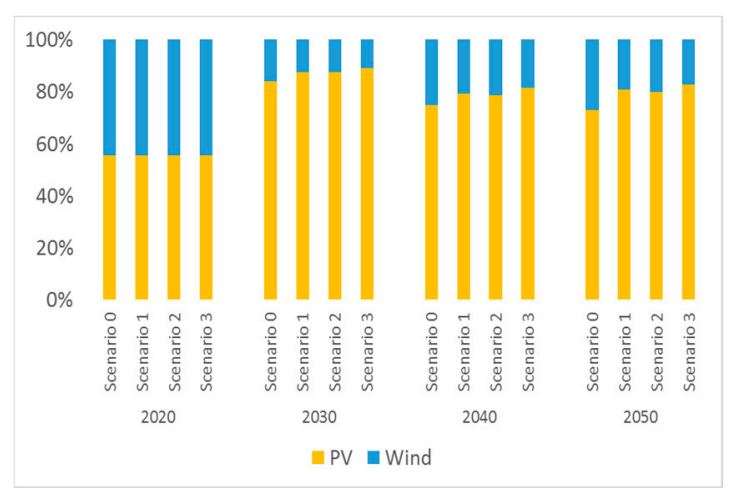

(a)

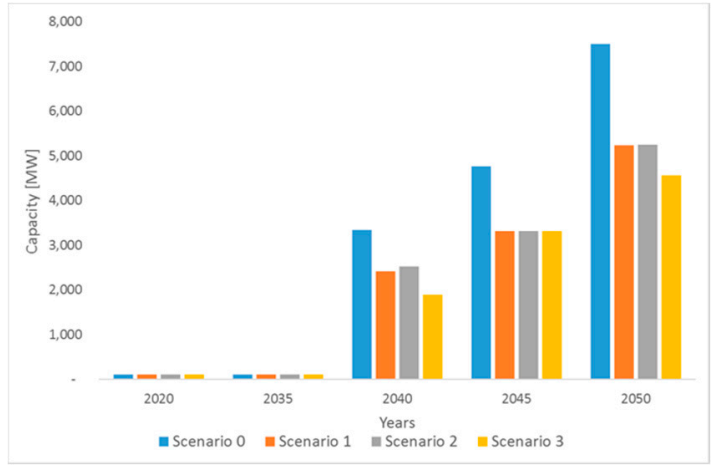

(b)

Figure 4. Relative evolution of PV and wind installed capacity per scenario (a) and evolution of the installed capacity of CSP (b).

Figure 5a shows that the emission factor of the system decreases drastically even in the scenario with no storage, reaching $22 \%$ of the value at 2020 by 2050 . This is mainly due to the decommissioning of $3010 \mathrm{MW}$ of coal generation during this period, representing $58 \%$ of 2020 's coal installed capacity. This also explains the large decrease of the emission factor in 2040, when $1300 \mathrm{MW}$ of coal are decommissioned. This result underlines the importance of a planned decommissioning of the ageing coal power generators.

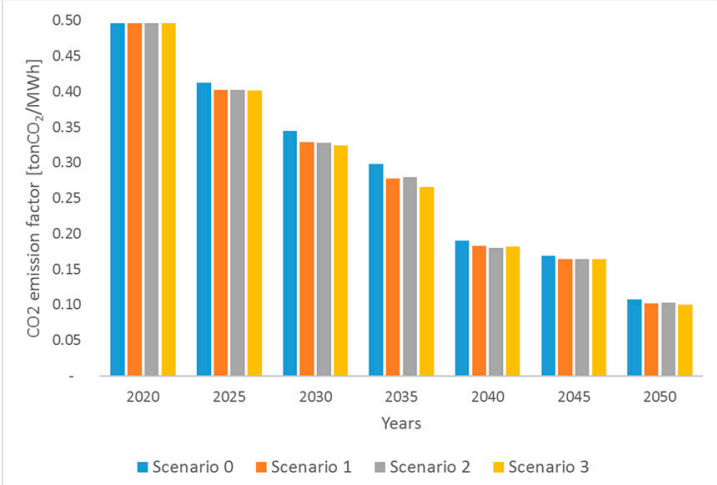

(a)

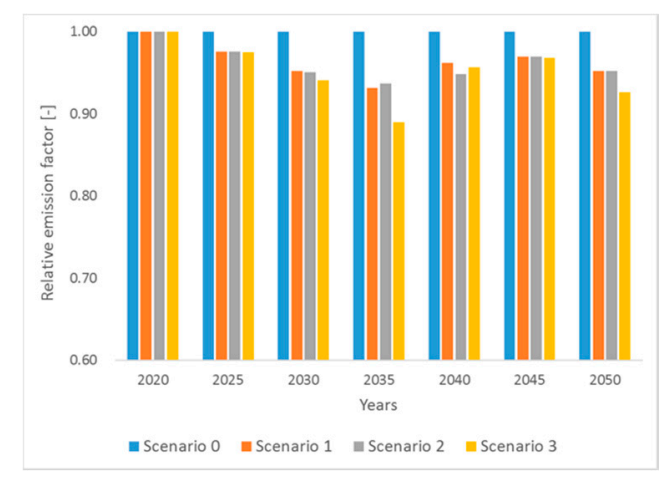

(b)

Figure 5. Evolution of the absolute emission factor (a) and the relative emission factor for Scenarios 1, 2 and 3 with respect to Scenario $0(\mathbf{b})$.

As the difference in emission factors between the scenarios is small compared to the overall decrease, Figure $5 \mathrm{~b}$ presents the variation of each scenario with respect to Scenario 0, which is considered here as a reference. The reason for the relatively small emission factor difference between Scenario 0 and the other scenarios (even though the difference in installed wind + PV generation is larger) is that, in absence of electricity storage, in Scenario 0 there is a rise in the installed capacity of dispatchable CSP, as shown in Figure $4 \mathrm{~b}$. This, however, has an impact on the investment costs of the system (Figure 6b), as CSP is a much more capital intensive technology than PV. 


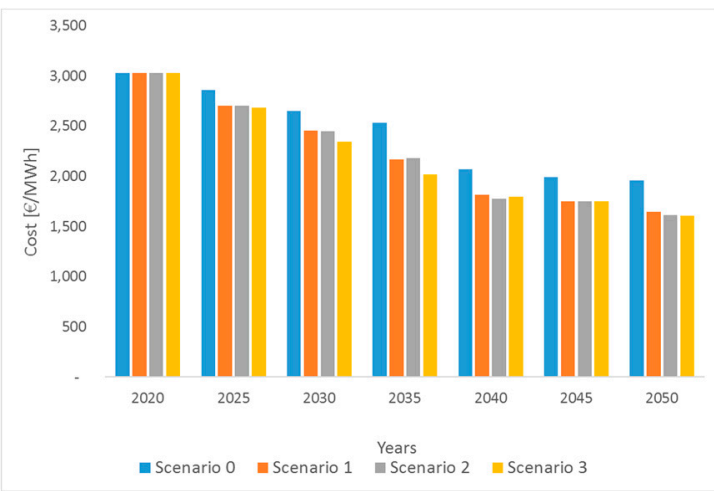

(a)

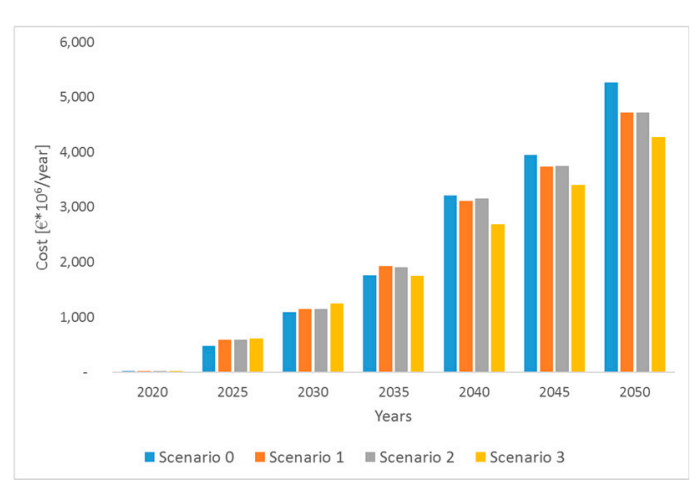

(b)

Figure 6. Evolution of the operational cost (a) and the annualized investment cost (b) for Scenarios 1, 2 and 3.

It is clear that the change of the emissions is not monotonic, as the problem represents a system with many different interacting constraints that leads to complex and unexpected behaviour. For example, for 2035, Scenario 2 presents a higher emission factor than Scenario 1, despite having more energy storage and PV generation capacity. The explanation for this particular case, is that the higher energy storage capacity is not enough to balance the extra PV generation by its own and CCGT has to run for more hours to balance the extra PV generation.

Figure 6a presents the costs of operating the system for one year, including fuel and other fixed and variable costs, whereas Figure $6 \mathrm{~b}$ shows the annualized costs of investments in every year. It must be noted that these costs are cumulative, because the annualized cost of an investment is applied until the end of its life, which explains the general increasing trend. Figure $6 \mathrm{a}$, on the other hand, presents a decreasing trend, which is explained mostly by the decrease of fuel consumption due to the increase in renewable generation penetration.

Figure $6 \mathrm{~b}$ shows that after 2040, the scenarios with storage have lower investment costs than Scenario 0 . This is due the possibility to include cheap renewable generation (as PV) backed by the existent storage. Scenario 0 , on the other hand, must install more expensive renewable technologies, such as CSP, as it has not enough storage to back the operation of non-dispatchable renewable generation.

From the results, it is evident that Scenario 2 ( $30 \mathrm{~h}$ of storage) achieves only a small improvement compared with Scenario 1 ( $8 \mathrm{~h}$ of storage), despite having almost 4 times more storage capacity. This agrees with the results presented in Section 3.2 which shows that the optimal energy storage size is around $9 \mathrm{~h}$. Scenario 3 is the one that achieves the highest cost reduction with respect to Scenario 0, reaching an 18\% decrease in operational cost and a 19\% in accumulated investment by 2050 .

As Scenarios 1, 2 and 3 consider storage to be given, the difference in costs with Scenario 0 represents the maximum cost that energy storage can have in order to make the system at least as cheap as the case without storage. Scenario 1 is analysed to find this maximum cost of storage assuming an energy storage system cost per MWh of capacity (no additional cost per power capacity) and another with cost per MW (zero cost of additional energy capacity).

Table 7 presents the maximum investment costs of storage for these two cases on an annual basis. It shows that in order to be economically attractive to install the amount of storage in Scenario 1 in 2025 it has to cost less than $43 € / \mathrm{kWh}$, which is well below the predictions of long term utility battery storage for 2025 (350€/kWh [39] $530 € / \mathrm{kWh}$ [40]). Although this cost could be achieved with pumped hydro [41], the availability of the cheapest hydro resource is located in the south, while the main requirement of storage is in the north, where current cost estimates for this technology are around $1400 € / \mathrm{kW}$ (although cost estimates are around $10 € / \mathrm{kWh}$ on an energy basis) [13]. Costs for storage added after 2035 is probably achievable, however, the benefits calculated for these years consider that cheaper storage was installed in the previous years. 
Table 7. Maximal annualized investment costs of storage based on energy and power capacity, respectively.

\begin{tabular}{ccccccc}
\hline & $\mathbf{2 0 2 5}$ & $\mathbf{2 0 3 0}$ & $\mathbf{2 0 3 5}$ & $\mathbf{2 0 4 0}$ & $\mathbf{2 0 4 5}$ & $\mathbf{2 0 5 0}$ \\
\hline Maximum investment cost $[€ / \mathrm{kWh}]$ & 43 & 144 & 139 & 166 & 158 & 542 \\
Maximum investment cost $[€ / \mathrm{kW}]$ & 340 & 1155 & 1110 & 1370 & 1230 & 4330 \\
\hline
\end{tabular}

This analysis shows that it is not realistic to achieve the rates of storage deployment presented in these scenarios. A more realistic approach with real storage technologies costs included in the optimisation must be analysed.

\subsection{Scenarios 4 and 5}

In contrast with Scenarios 1, 2 and 3, Scenarios 4 and 5 include the energy storage as well as the transmission capacity (only Scenario 5 ) in the optimization problem. For these scenarios, storage deployment starts after 2040 when PTES investment costs are expected to reach $500 € / \mathrm{kW}$ according to Table 6. The optimal amount of storage in each node for year 2050 is presented in Table 8.

Table 8. Installed capacity of storage in year 2050 for Scenarios 4 and 5 after running the model.

\begin{tabular}{ccccccc}
\hline & & Node 1 & Node 2 & Node 3 & Node 4 & Total \\
\hline \multirow{2}{*}{ Scenario 4 } & Storage power by 2050 [MW] & 1377 & 1508 & 761 & 0 & 3646 \\
& Storage energy by 2050 [h] & 12 & 7.5 & 7 & 0 & 9.1 \\
Scenario 5a & Storage power by 2050 [MW] & 1535 & 1605 & 593 & 0 & 3734 \\
& Storage energy by 2050 [h] & 11.3 & 7.3 & 6.8 & 0 & 8.9 \\
Scenario & Storage power by 2050 [MW] & 1500 & 1682 & 557 & 0 & 3740 \\
5b & Storage energy by 2050 [h] & 11.7 & 7.4 & 7.4 & 0 & 9.1 \\
\hline
\end{tabular}

Table 8 confirms that energy storage presents higher value in supporting solar generation (PV) rather than wind, as the storage capacity concentrates in the sunniest northern nodes (Node 1 and 2) and no storage is installed in Node 4, the node with lowest solar and highest wind resources. Also, it shows that the optimal energy capacity for storage is around $9 \mathrm{~h}$ but shows a difference between the optimal energy storage capacity of Node 1 and Nodes 2 and 3. This difference is due to the different energy demand profiles. The demand in Nodes 2 and 3 is dominated by residential consumers and usually peaks around 21:00 to 23:00 and decreases sharply during the night (01:00 to 06:00). This means, that in Nodes 2 and 3, a 7-8 h storage capacity is enough to shift the solar energy production peak from 14:00 to the late evening peak. In Node 1, on the other hand, demand is dominated by the mining industry and is comparatively flatter and does not have the sudden decrease at night, which means that the energy stored during the day has to be retrieved over a longer period.

Scenario 5 also includes transmission expansion in the optimization. The result of this transmission expansion optimization is presented in Table 9 up to the year 2050. As expected, a cheaper cost of transmission investment tends to increase the expansion of the transmission system. However, this expansion takes effect only after 2045 and concentrates in the line connecting Nodes 2 and 3 , which is used mainly to transfer cheap solar PV from the northern part of the former SIC to the main consumption point in central Chile and under a cost of 550,000 $€ / \mathrm{km}$ should more than double. The connection between Nodes 1 and 2, is not expected to increase, as Node 2 has enough PV potential to supply Node 3 and there is no need to send energy from Node 1 to Node 3. 
Table 9. Transmission capacity for Scenario 5.

\begin{tabular}{lllllll}
\hline & & \multicolumn{5}{c}{ Transmission Capacity [MW] } \\
\cline { 3 - 7 } & & $\mathbf{2 0 2 0}$ & $\mathbf{2 0 3 0}$ & $\mathbf{2 0 4 0}$ & $\mathbf{2 0 4 5}$ & $\mathbf{2 0 5 0}$ \\
\hline \multirow{3}{*}{ Scenario 5a } & Node 1-Node 2 & 1500 & 1500 & 1500 & 1500 & 1500 \\
& Node 2-Node 3 & 1500 & 1500 & 1500 & 1783 & 2898 \\
& Node 3-Node 4 & 2000 & 2000 & 2000 & 2000 & 2000 \\
\hline \multirow{3}{*}{ Scenario 5b } & Node 1-Node 2 & 1500 & 1500 & 1500 & 1500 & 1500 \\
& Node 2-Node 3 & 1500 & 1500 & 1500 & 2200 & 3543 \\
& Node 3-Node 4 & 2000 & 2000 & 2000 & 2054 & 2287 \\
\hline
\end{tabular}

Figure 7a presents the evolution of the installed capacity of PV and wind generation, while Figure $7 \mathrm{~b}$ presents the trend of the energy generated by these technologies for Scenarios 4, $5 \mathrm{a}$ and $5 \mathrm{~b}$, with Scenario 0 as reference. If comparing Figure 7 with the results for the first three scenarios presented in Figure 3, it is clear that the installed capacity of PV and wind increases less. It is interesting to note that the installed capacity of non-dispatchable renewables in Scenarios 4 and 5 in 2050 is similar to the installed capacity in Scenarios 1,2 and 3 in 2035. This shows that the ability to integrate PV and wind generation in the energy system is related to the amount of energy storage.

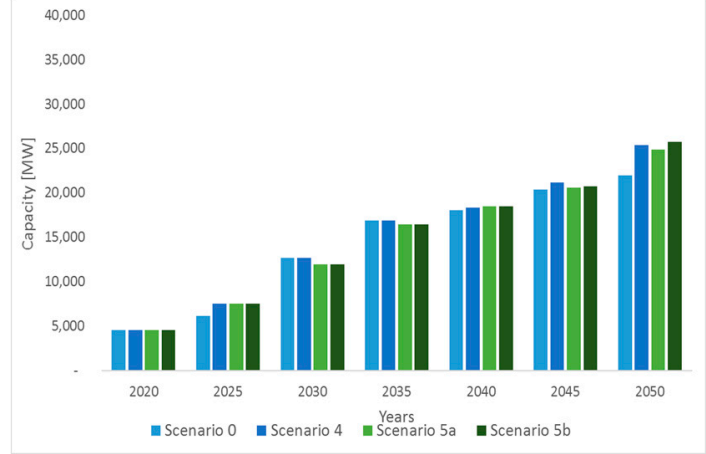

(a)

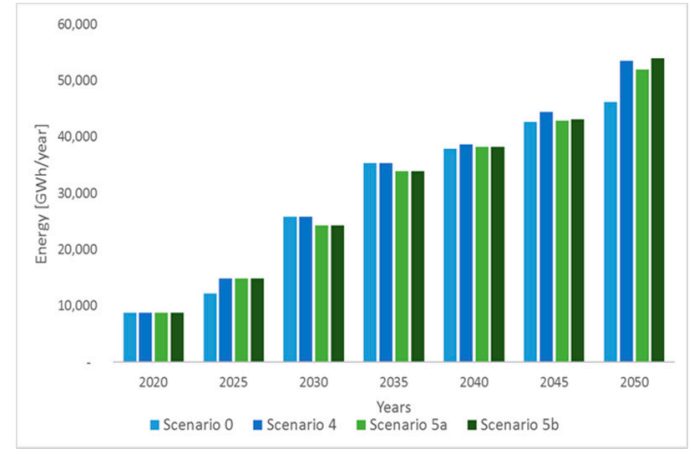

(b)

Figure 7. Evolution of the installed capacity (a) and energy generation (b) of PV and wind for Scenarios 4 and 5.

Figure 8a presents the absolute emission factor of the system for the different scenarios, while Figure $8 \mathrm{~b}$ presents their evolution relative to Scenario 0 . Similarly to Figure $5 \mathrm{a}$, it is evident that the general decreasing trend is driven by the decommissioning of ageing coal generation. In contrast to Scenarios 1 to 3, this figure shows that Scenarios 4 and 5 have relatively higher emissions than Scenario 0 . This is counter-intuitive, especially for Scenario 4 , as it has the same transmission expansion than Scenario 0 but also has the option of installing energy storage, which allows an increase in the installed capacity of PV and wind. However, as the solar resource is particularly good in northern Chile, CSP with thermal storage becomes competitive with conventional options and is installed instead. 


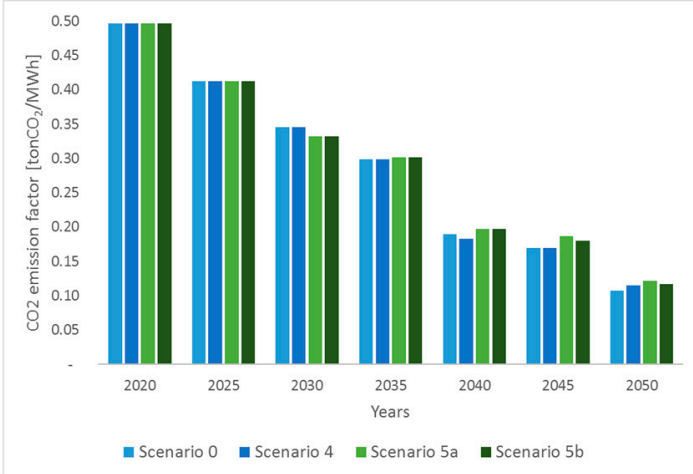

(a)

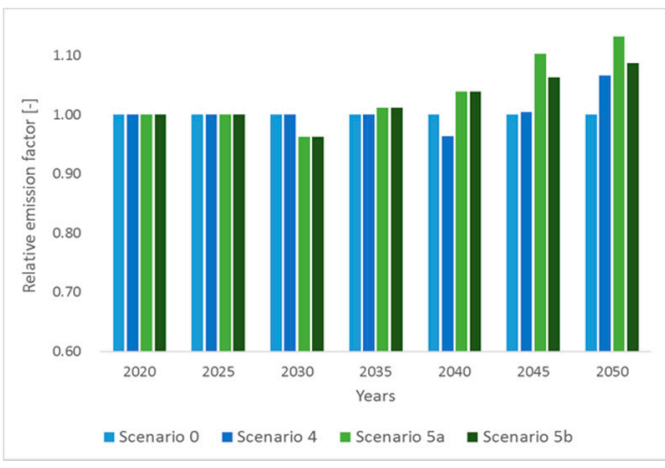

(b)

Figure 8. Evolution of the absolute emission factor (a) and the relative emission factor with respect to Scenario 0 (b) for Scenarios 4 and 5.

Again, it can be seen that the change of the emissions is not monotonic, due to the many different interacting constraints. For example, in 2040 Scenario's 4 emission factor decreases with respect to Scenario 0 but in 2050 it increases. The decrease of the emission factor in 2040 comes from the fact that in Scenario 0, the absence of storage in Node 2 causes $600 \mathrm{MW}$ more CCGT to be installed in Node 3, in contrast to Scenario 4, where PV plus energy storage in Node 3 is installed. In 2050, on the other hand, it is cheaper for the system in Scenario 4 to operate with PV with storage and coal than with extra CSP, so there are more emissions that in Scenario 0 are avoided by installing a higher amount of more expensive CSP.

Figure 9a presents the costs of operating the system for one year, including fuel and other fixed and variable costs, whereas Figure $9 \mathrm{~b}$ shows the cumulated annualized costs of investments in every year. The trends of both figures are similar to those in Figure 6. However, if compared with Scenarios 1, 2 and 3, the cost reductions in Scenarios 4 and 5 are lower. This is especially evident in the investment costs, as in this case there is a cost for installing energy storage and for expanding the transmission system (Scenario 5). In the case of the operational cost, the decrease is comparatively lower as the amount of total installed energy storage is lower, meaning that more fuel has to be burned to meet the demand. However, there is still an important cost reduction with respect to Scenario 0. In particular, the most realistic of the scenarios (Scenario $5 \mathrm{~b}$ ) reaches a $6 \%$ decrease of the annual system operation cost and accumulated investment cost by 2050 compared to Scenario 0 .

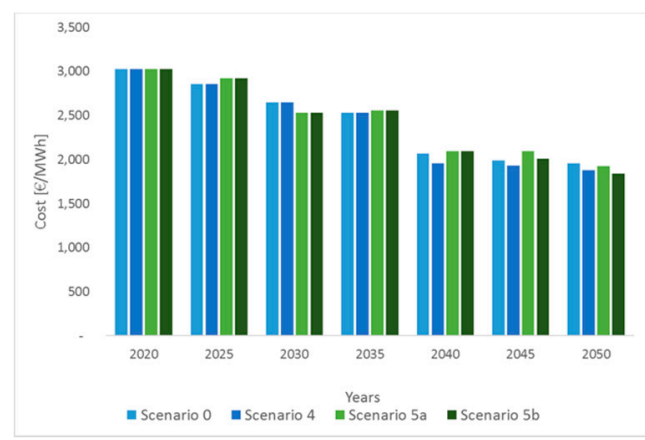

(a)

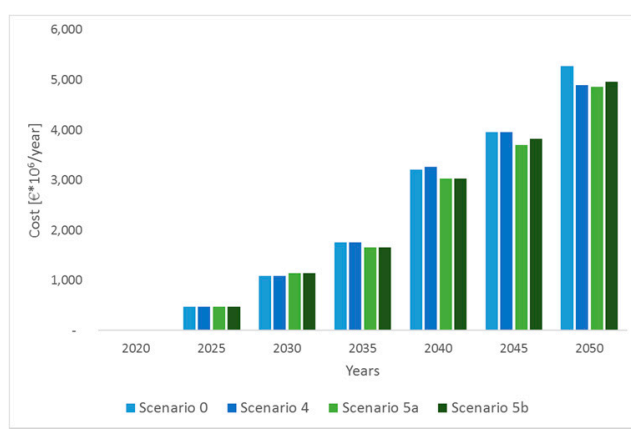

(b)

Figure 9. Evolution of the operational cost (a) and annualized investment cost (b) for Scenarios 4 and 5.

The previous results and analysis have mainly assessed the achievable scenarios of non-dispatchable renewable generation and emissions at a country level. Figure 10 complements that analysis by presenting the geographical distribution of the energy generation of the different technologies for four of the analysed scenarios by 2050. Although in all scenarios the total annual generated solar energy represents around $50 \%$ of the total energy generated in that year, the most 
obvious difference between the scenarios is the relative participation of PV and CSP generation. As mentioned previously, a higher amount of energy storage in the grid shifts the solar installed capacity from CSP to PV, as a combination of PV plus a PTES-like storage system is cheaper than CSP with molten salt storage.

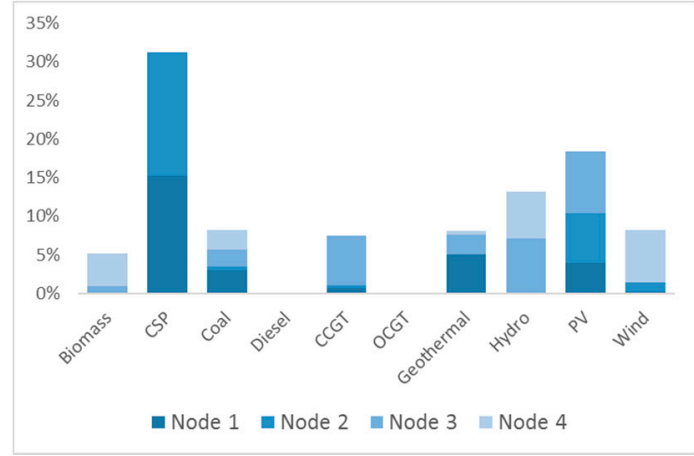

(a)

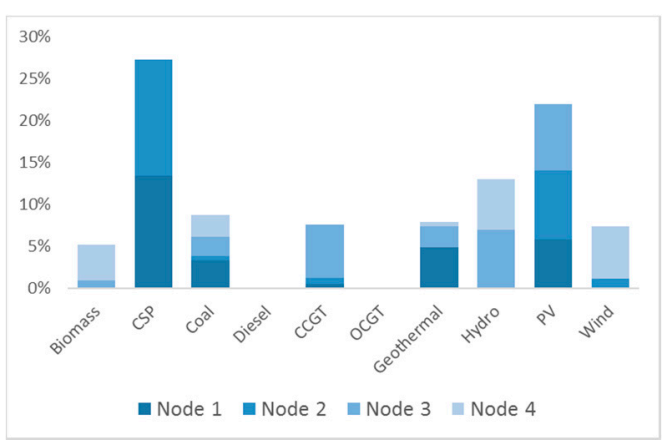

(c)

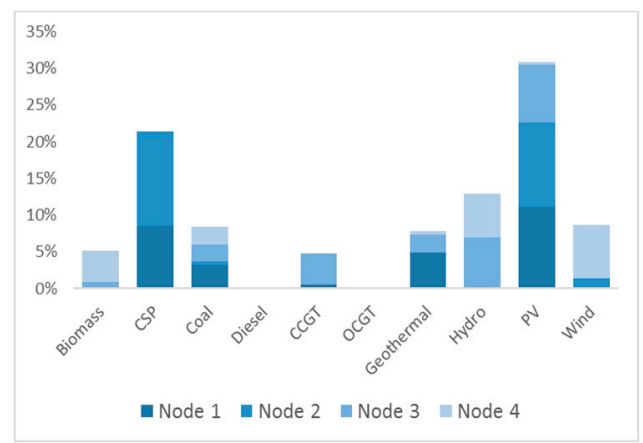

(b)

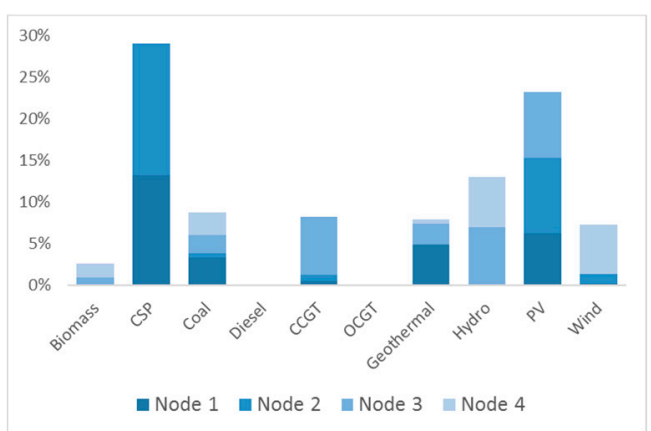

(d)

Figure 10. Distribution of energy generation by technology in each node for year 2050, Scenario 0 (a), Scenario 1 (b), Scenario 4 (c) and Scenario 5 b (d).

According to the model, for all the analysed scenarios, the $70 \%$ renewable generation goal by 2050 is reached. Even more, $70 \%$ is reached in most of the scenarios without considering hydroelectric energy, as shown in Table 10. Despite being in accordance with results found by Munoz et al. [5], this result is probably a slight overestimation of the total amount of non-dispatchable renewable generation achievable under these scenarios.

Table 10. Percentage of energy coming from renewable generation including and excluding hydro power stations in year 2050 for all the scenarios.

\begin{tabular}{cccccccc}
\hline & \multicolumn{7}{c}{ Scenarios } \\
\hline & $\mathbf{0}$ & $\mathbf{1}$ & $\mathbf{2}$ & $\mathbf{3}$ & $\mathbf{4}$ & $\mathbf{5 a}$ & $\mathbf{5 b}$ \\
\hline Ren. Generation w/o hydro [\%] & $71.1 \%$ & $73.8 \%$ & $74.2 \%$ & $74.6 \%$ & $70.7 \%$ & $68.8 \%$ & $70.1 \%$ \\
\hline Ren. Generation with hydro [\%] & $84.3 \%$ & $86.7 \%$ & $87.1 \%$ & $87.4 \%$ & $83.7 \%$ & $81.8 \%$ & $83.1 \%$ \\
\hline
\end{tabular}

The main source of possible overestimation of renewable generation integration in the current linear optimization model is the lack of a constraint to limit the minimum operational range of conventional generation such as coal and CCGT, which overestimates the capacity of these technologies to back changes in non-dispatchable renewable generation. Also, the current nodal resolution of the model does not allow to assess possible local constraints that could lead to transmission bottlenecks in renewable-resource rich clusters located at a certain distance from the main transmission lines. 
In any case, although it is expected that the inclusion of these missing features would decrease the total amount of renewables for a given scenario, it also is expected to increase the value of storage in the grid.

Another feature that determines the results of this model is that as every period is run independently, the system is agnostic of the demand and prices variation in the future. This assumption usually leads to less economically optimal system configurations but is probably more realistic due to the uncertainty in long-term fuel price and technology cost predictions.

Finally, the fact that transmission can be expanded in a continuous way, instead of in large discrete steps, promotes earlier transmission expansion. This also could lead to an overestimation of non-dispatchable renewable generation, because as shown in Figure $7 \mathrm{a}$, a delay in the transmission expansion causes a decrease in PV and wind penetration.

\section{Conclusions}

This paper assesses the impact of grid level energy storage on the decarbonisation of the Chilean electricity system. Efficient optimization methods are required to find the optimal design and operation of the electric system due to the large size of the problem and the complex interplay between generation, transmission and energy storage. In this study, a linear programming model optimizing the design and operation of the Chilean electricity system has been developed.

The linear optimization model uses the urbs framework, which was expanded with the ability to handle reservoir hydro generation and CSP with storage plants. The Chilean electric system is modelled with four nodes representing the main parts of the system. Several scenarios are run for renewable generation, energy storage and transmission expansion between 2020 and 2050. These scenarios start with the current configuration of the electric system and evaluate different energy storage and transmission expansions. The problem is separated into independent expansion and annual operation problems, linked by the installed capacity of transmission, energy generation and storage technology.

The analysis shows that the main source of the grid emission factor decrease is the decommissioning of coal based generation and its replacement by a mix of solar generation and CCGT. The differences of emission factor between any scenario in 2050 is very small in comparison with the decrease due to coal decommissioning (less than $5 \%$ of the emission factor in 2020 and less than 0.025 tonCO $\mathrm{CO}_{2} / \mathrm{MWh}$ in absolute terms). This means that in order to achieve a $78 \%$ decrease in emission factor by 2050, it is necessary to ensure a policy that would internalize coal based generation's externalities and encourage the decommissioning of the ageing units.

The analysis shows that storage, with a carbon tax of $5 € /$ ton $\mathrm{CO}_{2}$, not necessarily decreases the emission factor of the system in the long term. This is mainly because at that level of carbon price, it is often cheaper to run the existing coal generation instead of installing more low emitting technologies. However, its addition decreases the operational cost of the system and enables the higher deployment of relatively cheaper non-dispatchable renewable technologies. For the Chilean system, the integration of energy storage leads to higher deployment of solar PV systems compared to wind turbines due to the very good solar resource and the strong synergy of the daily solar cycle with energy storage capacities of around half a day. While there are currently no plans to increase the carbon tax in Chile, it would be worthwhile to evaluate the effect of different carbon tax scenarios in a future study.

For the most realistic case with storage costs like those projected for Pumped Thermal Energy Storage (PTES), the addition of storage could save $6 \%$ in annual system operation costs and in the total investment cost in generation from 2020 to 2050. As it shows high synergies with solar PV, this storage is more optimally located in the northern part of the country. Because in that area of the country there is no possibility of installing cheap pumped hydro energy storage, the option of installing a PTES-like storage appears especially attractive. The optimal storage capacities show good agreement with the demand profiles of the different nodes. The optimal storage capacity for the northern node is around $12 \mathrm{~h}$ due to the flatter demand profile which is dominated by the continuously operating mining 
industry. On the other hand, the two central nodes are dominated by residential customers which have a lower night time demand and consequently the optimal storage capacity is lower at around $7 \mathrm{~h}$.

In further works, it would be interesting to perform a comparative analysis between installing PTES-like storage in the northern area of Chile against locating potentially cheaper pumped hydro storage in the south.

Author Contributions: Conceptualization, S.A.M. and D.F.; Methodology, S.A.M. and D.F.; Software, S.A.M.; Validation, S.A.M.; Formal analysis, S.A.M.; Investigation, S.A.M. and D.F.; Resources, S.A.M.; Data curation, S.A.M.; Writing —original draft preparation, S.A.M.; Writing—Review and editing, G.P.H. and D.F.; Visualization, S.A.M.; Supervision, G.P.H. and D.F.; Project administration, D.F.; Funding acquisition, S.A.M.

Funding: This research was funded by a PhD Scholarship from CONICYT PFCHA/DOCTORADO BECAS CHILE/2017-72180200.

Conflicts of Interest: The authors declare no conflict of interest.

\section{Appendix A}

Table A1. Projected investment costs of renewable generation and of fuels.

\begin{tabular}{|c|c|c|c|c|c|c|c|c|}
\hline & & 2020 & 2025 & 2030 & 2035 & 2040 & 2045 & 2050 \\
\hline $\mathrm{PV}^{1}$ & \multirow{5}{*}[€/\mathrm{kW}]{} & 923 & 799 & 717 & 668 & 616 & 561 & 504 \\
\hline CSP & & 6315 & 5626 & 4937 & 4592 & 4248 & 4133 & 4018 \\
\hline Wind & & 1490 & 1408 & 1326 & 1245 & 1163 & 1082 & 1000 \\
\hline Biomass & & 2611 & 2565 & 2520 & 2474 & 2429 & 2394 & 2360 \\
\hline Geothermal & & 5429 & 5293 & 5157 & 5021 & 4884 & 4748 & 4721 \\
\hline Diesel & \multirow{4}{*}[€/\mathrm{MWh}]{$^{2}$} & 56.3 & 63.5 & 68.7 & 73.4 & 77.9 & 79.6 & 82.6 \\
\hline Natural Gas & & 32.4 & 32.4 & 34.3 & 34.6 & 34.6 & 35.9 & 37.4 \\
\hline Coal & & 9.6 & 9.7 & 9.7 & 9.8 & 10 & 10 & 10 \\
\hline Biomass & & 9.7 & 9.7 & 9.7 & 9.7 & 9.7 & 9.7 & 9.7 \\
\hline
\end{tabular}

${ }^{1}$ For nodes 3 and 4 the cost is considered to be $35 \%$ higher due to high presence of rooftop generation. ${ }^{2}$ Corresponds to the thermal energy of the fuel.

\section{References}

1. CDEC-SING. Efectos Técnico-Económicos De La Integracion de Energía Eeólica y Solar en e SING: Escenario Año 2015; CDEC-SING: Santiago, Chile, 2012.

2. Comisión Nacional de Energía Energía Abierta-Capacidad Total Instalada. Available online: http:// energiaabierta.cl/visualizaciones / capacidad-instalada/ (accessed on 30 January 2019).

3. Comité Consultivo de Energía 2050. Hoja de Ruta 2050; Comité Consultivo de Energía: Santiago, Chile, 2015.

4. International Energy Agency. Energy Policies Beyond IEA Countries-Chile Review 2018; International Energy Agency: Paris, France, 2018.

5. Munoz, F.D.; Pumarino, B.J.; Salas, I.A. Aiming low and achieving it: A long-term analysis of a renewable policy in Chile. Energy Econ. 2017, 65, 304-314. [CrossRef]

6. Haas, J.; Palma-Behnke, R.; Valencia, F.; Araya, P.; Díaz-Ferrán, G.; Telsnig, T.; Eltrop, L.; Díaz, M.; Püschel, S.; Grandel, M.; et al. Sunset or sunrise? Understanding the barriers and options for the massive deployment of solar technologies in Chile. Energy Policy 2018, 112, 399-414. [CrossRef]

7. Nasirov, S.; Silva, C.; Agostini, C.A. Investors' Perspectives on Barriers to the Deployment of Renewable Energy Sources in Chile. Energies 2015, 8, 3794-3814. [CrossRef]

8. Hu, J.; Harmsen, R.; Crijns-Graus, W.; Worrell, E.; van den Broek, M. Identifying barriers to large-scale integration of variable renewable electricity into the electricity market: A literature review of market design. Renew. Sustain. Energy Rev. 2018, 81, 2181-2195. [CrossRef]

9. Forrester, S.P.; Zaman, A.; Mathieu, J.L.; Johnson, J.X. Policy and market barriers to energy storage providing multiple services. Electr. J. 2017, 30, 50-56. [CrossRef] 
10. Moreno, R.; Ferreira, R.; Barroso, L.; Rudnick, H.; Pereira, E. Facilitating the Integration of Renewables in Latin America: The Role of Hydropower Generation and Other Energy Storage Technologies. IEEE Power Energy Mag. 2017, 15, 68-80. [CrossRef]

11. Suazo-Martínez, C.; Pereira-Bonvallet, E.; Palma-Behnke, R. A simulation framework for optimal energy storage sizing. Energies 2014, 7, 3033-3055. [CrossRef]

12. White, A.; Parks, G.; Markides, C.N. Thermodynamic analysis of pumped thermal electricity storage. Appl. Therm. Eng. 2013, 53, 291-298. [CrossRef]

13. Valhalla Energy Espejo de Tarapaca. Available online: http://valhalla.cl/espejo-de-tarapaca/ (accessed on 7 February 2019).

14. Steinmann, W.-D. Thermo-mechanical concepts for bulk energy storage. Renew. Sustain. Energy Rev. 2017, 75, 205-219. [CrossRef]

15. McTigue, J.D.; White, A.J.; Markides, C.N. Parametric studies and optimisation of pumped thermal electricity storage. Appl. Energy 2015, 137, 800-811. [CrossRef]

16. Smallbone, A.; Jülch, V.; Wardle, R.; Roskilly, A.P. Levelised Cost of Storage for Pumped Heat Energy Storage in comparison with other energy storage technologies. Energy Convers. Manag. 2017, 152, 221-228. [CrossRef]

17. Revista de Electricidad Baterías en Chile buscan dar un paso más en Servicios Complementarios. Available online: http:/ / www.revistaei.cl/informes-tecnicos/baterias-chile-buscan-dar-paso-mas-servicioscomplementarios / (accessed on 10 January 2019).

18. Dorfner, J. Urbs Documentation—Release 0.7.1 2018. Available online: https://media.readthedocs.org/pdf/ urbs/stable/urbs.pdf (accessed on 18 December 2018).

19. Van-Rossum, G. Python Software Foundation. Python Language Reference; Version 3.2.7; Network Theory Ltd.: MA, USA, 1995; Available online: https:/ / docs.python.org/3/reference/ (accessed on 8 February 2019).

20. Hart, W.E.; Watson, J.-P.; Woodruff, D.L. Pyomo: Modeling and solving mathematical programs in Python. Math. Prog. Comp. 2011, 3, 219-260. [CrossRef]

21. Gurobi Optimization Inc Gurobi Optimizer 2010. Available online: https://www.gurobi.com/ documentation/8.1/refman/index.html (accessed on 8 February 2019).

22. Coordinador Eléctrico Nacional Map-Sistemas Eléctricos de Chile $20172017 . \quad$ Available online: https:/ / sic.coordinador.cl/wp-content/uploads/2013/06/Mapa-Coordinador-Electrico-01.jpg (accessed on 11 December 2018).

23. Ministerio de Energía de Chile. Proyectos en Construcción e Inversión en Sector Energía a Septiembre 2017; Ministerio de Energía de Chile: Santiago, Chile, 2017.

24. Lima, R.J.L.; Rivera, J.; Palma, R.; Jimenez, G.; Benavente, J.M.; Castillo, E. Informe Costo de Falla; Ministerio de Energía de Chile: Santiago, Chile, 2012.

25. Ministerio de Energía de Chile. Proceso de Planificación Energética de Largo Plazo; Ministerio de Energía de Chile: Santiago, Chile, 2018.

26. Coordinador Eléctrico Nacional. Available online: https:/ / www.coordinador.cl (accessed on 20 January 2019).

27. Ministerio de Energía de Chile. Balance Nacional de Energía Regional; Ministerio de Energía de Chile: Santiago, Chile, 2017.

28. Pfenninger, S.; Staffell, I. Renewables.ninja. Available online: https://www.renewables.ninja (accessed on 27 March 2018).

29. Vargas, X.; Ayala, Á.; Meza, R.; Rubio, E. Disponibilidad Futura de los Recursos Hídricos Frente a Escenarios de Cambio Climático en Chile; Ministerio de Energía de Chile: Santiago, Chile, 2012.

30. Santana, C.; Falvey, M.; Ibarra, M.; García, M. Energías Renovables en Chile; Ministerio de Energía de Chile: Santiago, Chile, 2014.

31. Energy Live Chile Agrees to Phase Out Coal Power Plants. Available online: https://www.energylivenews. com/2018/02/01/chile-agrees-to-phase-out-coal-power-plants/ (accessed on 20 January 2019).

32. Bravo, R.; Friedrich, D. Two-stage optimisation of hybrid solar power plants. Sol. Energy 2018, 164, 187-199. [CrossRef]

33. Parsons Brinckerhoff. Coal and Gas Assumptions, DECC; $2014 . \quad$ Available online: https: / / assets.publishing.service.gov.uk/government/uploads/system/uploads/attachment_data/file/ 315717/coal_and_gas_assumptions.PDF (accessed on 13 February 2019). 
34. BEIS. Electricity Generating Costs; BEIS, 2016. Available online: https://assets.publishing.service.gov. uk/government/uploads/system/uploads/attachment_data/file/566567 / BEIS_Electricity_Generation_ Cost_Report.pdf (accessed on 13 February 2019).

35. Agostini, C.A.; Silva, C.; Nasirov, S. Failure of energy mega-projects in Chile: A critical review from sustainability perspectives. Sustainability 2017, 9, 1073. [CrossRef]

36. Bardeen, S. International Rivers. Available online: https://www.internationalrivers.org/blogs/433/victoryin-chile-dams-scrapped-on-five-rivers (accessed on 31 January 2019).

37. World Bank. State and Trends of Carbon Pricing 2018; World Bank: Washington, DC, USA, 2018.

38. Ministerio del Medio Ambiente Chile's Green Tax. 2018. Available online: https://www.4echile.cl/4echile/ wp-content/uploads/2018/05/1.-Strategy.-Chile\%C2\%B4s-Green-Tax.pdf (accessed on 5 February 2019).

39. Hayward, J.; Graham, P. Electricity Generation Technology Cost Projections 2017-2050; World Bank: Washington, DC, USA, 2017.

40. Schmidt, O.; Hawkes, A.; Gambhir, A.; Staffell, I. The future cost of electrical energy storage based on experience rates. Nat. Energy 2017, 2, 1-8. [CrossRef]

41. IRENA. Electricity Storage and Renewables: Cost and Markets to 2030; IRENA: Abu Dhabi, UAE, 2017.

(C) 2019 by the authors. Licensee MDPI, Basel, Switzerland. This article is an open access article distributed under the terms and conditions of the Creative Commons Attribution (CC BY) license (http:/ / creativecommons.org/licenses/by/4.0/). 